\title{
Control Structure between Removal and Movement: Evidence from Modern Standard Arabic
}

\author{
Noura F. Abdou \\ Department of English Linguistics, Faculty of Languages, Literature and Cultural Studies, University of Regensburg, 93053, Regensburg, \\ Germany \\ *Corresponding Author:stella_lavina@yahoo.com
}

Copyright (C) 2013 Horizon Research Publishing All rights reserved.

\begin{abstract}
This paper investigates control structure in Modern Standard Arabic (MSA) in light of the current discussions that are revolving around either removing the control construction from the grammar because it is just like raising construction or retaining it. The Minimal Distance Principle (MDP) is applied in MSA in light of Landau's argument to clarify whether promise-type verbs are highly marked exceptions as claimed by Hornstein or not. This investigation explains that promise-type verbs are not highly marked. The pieces of evidence provided by the MSA examples point out that control structure is not a raising structure; thus the former cannot be reduced to the latter.
\end{abstract}

Keywords PRO, Movement Theory of Control, Minimal Distance Principle, Promise-Type Verbs, Modern Standard Arabic, Highly Marked Exceptions.

\section{Introduction}

Although control and raising structures have been viewed and handled differently since roughly the emergence of generative grammar, however, controversial points of view regarding this kind of distinction have been raised recently. On the one hand, Hornstein [1] argues in favor of treating control and raising similarly i.e. reducing control into raising. He claims that the removal of the control module, including the PRO theorem simplifies the grammar. He argues that Obligatory Control (OC) structures should be addressed in terms of movement, thus he initiates a Movement Theory of Control (MTC). On the other hand, Landau [2] argues against Hornstein's claims and supports maintaining the control module and distinguishing it from raising construction. In spirit of Landau [2], I argue that control cannot be reduced to raising. This is because the status of Minimal Distance Principle (MDP), which is advocated by Hornstein [1] to account for his MTC approach, cannot account for the choice of the controller of PRO especially with cases of promise-type verbs. Besides, promise-type cases should not be treated as "highly marked exceptions" as claimed by Hornstein. Examples from MSA serve as evidence in favor of my argument.

\section{Literature Review}

Hornstein $[1,3,4]$ argues that control and raising should be treated similarly. Thus, he claims that Obligatory Control structures (OC) are the result of movement. In this respect, PRO is just like an NP trace. Landau [2,5] provides arguments against the reductionist view of control. He argues that Hornstein's theory "overgenerates nonexisting structures and interpretations". He argues for the "standard view of control", the distinction between raising and control, and the existence of PRO. Culicover and Jackendoff [6-8] explain that in order to solve this problem of control, the latter "should be taken out of the hands of syntax and turned over to the semantics". Boeckx and Hornstein [9] try to support the Movement Theory of Control (MTC) in light of Icelandic language and Brazilian Portuguese (BP). Bobaljik and Landau [10] refuse Hornstein's claim and point out that PRO in Icelandic bears a structural case. Thus, the MTC has no distinction between PRO and lexical subjects. Modesto [11] points out that (BP), a language with inflected infinitives, is not compatible with the Movement Theory of Control.

\section{Theoretical Basis}

According to Hornstein [1] control constructions can be reduced to raising. Accordingly, obligatory control structures are formed in terms of movement. He claims that the control module and the PRO theorem derive problems to the Minimalist Theory such as the interpretation of PRO, the specification of the antecedent, the null case, and cases of control where PRO is in a position rather than (Spec, TP).

Thus, he proposes some alternatives such as; $\Theta$-roles are features transferred from predicates to DPs, there is no upper hand on the number of $\theta$-features an argument can have, sideward movement is permitted, greed is enlighted self interest, $\mathrm{A} D / \mathrm{NP}$ receives $\theta$-Roles by checking a $\theta$-feature 
of a verbal or predicative phrase that it merges with, there is no null case i.e the null subject of infinitives is caseless, and control is movement, subject to the Minimal Link Condition. Therefore, he is in favor of eliminating the control module, including PRO and the $\theta$-criterion, from the grammar.

Landau [2] notes empirical difficulties for the movement analysis of control. He contrasts the MTC with the standard view of control which consists of the following assumptions: PRO exists and it is distinct from NP trace, the control module exists, and control involves two argument chains, while raising involves one. In order to point out the previously mentioned difficulties, Landau proposes many arguments that cannot be supported or analyzed in light of the MTC. Some of these arguments are such as; control across passive, implicit controllers, sideward movement from complements, and the status of MDP.

\section{Minimal Distance Principle}

The MDP was proposed by Rosenbaum [12]; it states that the choice of the controller (antecedent) of PRO depends on the controller's proximity from the latter. Thus, the closest c-commanding noun phrase or determiner phrase from PRO is the controller in OC structures. Radford [13] states that there are two types of control verbs; subject control verbs and object control verbs. The controller of PRO is a subject in subject control verbs while in object control verbs the antecedent of PRO is always found to be an object.

Hornstein [1] uses the MDP as it is suitable for his MTC approach. According to the MDP and in light of the MTC the derivation of (1a) is explained in (1b):

(1a) John hopes to leave.

(1b) [IP John [VP John [hopes [IP John to [VP John leave]]]]

Since John is the closest NP to the embedded clause, so there is a case of subject control, according to the MDP. The DP John in the embedded clause to leave merges with the embedded VP, checking the external $\theta$-role of leave. Then, it raises to the embedded Spec IP position in order to check the EPP feature of to. Next, it raises to the matrix VP, receiving another $\theta$-role of hope. Finally, it moves to the matrix Spec IP position, where it checks nominative case and EPP features. Every time John moves, it leaves a copy of itself. Thus, there are two $\theta$-roles and one case. The same strategy applies to object control into complements.

Landau [2] argues that obligatory controllers have not been treated in terms of distance in approximately most of the studies that have been done on control. Landau illustrates that Hornstein's use of the MDP shows correct prediction of both subject and object control as in (2) and (3) respectively, but it improperly predicts object control in (4).

(2) Johni wanted [PROi to leave].

(3) Johni persuaded Maryj [PRO *i $/ \mathrm{j}$ to leave].

(4) Johni promised Maryj [PROi $/ * \mathrm{j}$ to leave].
In light of Landau's argument, the following MSA examples illustrate that the MDP manifest a proper interpretation of the controller in (5) and (6); subject and object control respectively, i.e the null PRO subjects in the embedded clauses refer back to the matrix subject Karaas in (5) and the matrix object Mariam in (6). The MDP fails to provide an interpretation of the controller in (7) .This is because according to MDP, the antecedent of PRO is the object Mariam since it is the closest noun phrase, although semantically the antecedent should be the subject Karaas.

$\begin{array}{ll}\text { (5) ?arad-a } & \text { Karaas1 ?an } \\ \text { wanted-he.3SG } & \text { Karaas.NOM that } \\ \text { ya-ðћab-a } & \text { PRO1 (subject control) } \\ \text { go.3SG. MASC } & \text { PRO } \\ \text { Karaas wanted to } & \end{array}$

Wo go.

(6) aqnac-a $\quad$ Karaas1 Mariam2 persuaded-he.3SG Karaas.NOM Mariam.ACC ?an ta- ðhab-a PRO*1/2 (object control) that go.3SG.FEM PRO

Karaas persuaded Mariam to leave.

(7) wacad-a $\quad$ Karaas1 Mariam2 promised-he.3SG Karaas.NOM Mariam.ACC ?an ya-ðhab-a PRO1/*2 (subject control) that go.3SG. MASC PRO

Karaas promised Maraim to go.

The embedded clause in the previous examples is introduced by the particle ?an "that". ?an in this construction has to precede a subjunctive verb, thus a noun phrase following it will render it ungrammatical [14].

Besides, the MDP incorrectly accounts for the antecedent of PRO in MSA dual construction because whenever a reference to a dual is used, the closest noun phrase to PRO is picked as the latter's antecedent, in accordance with the MDP [15]. To illustrate this, consider the following examples:

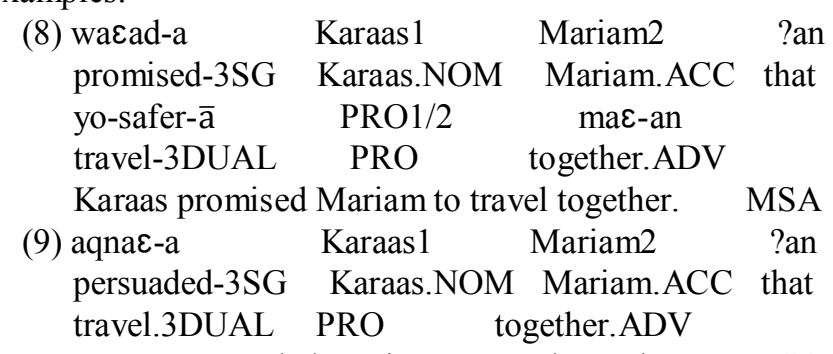

Karaas persuaded Mariam to travel together. MSA

In the previous examples; (8) and (9), the agreement (AGR) affix $\bar{a}$ (the morphologically bound dual pronoun) in yo-safer-ā "they both travel" agrees with the null subject PRO. This is because the AGR contains features that determine the subject-verb agreement in person, number, and gender $[14,16]$. Thus, the dual bound pronoun $\bar{a}$ in verb yo-safer- $\bar{a}$ carries third person, dual, masculine features which agree with PRO that in turn refers back to (is controlled by) both the matrix subject Karaas and the matrix object Mariam.

It is true that the MDP gives the right interpretation of the controller of PRO in (5) and (6), but this does not negate the result that MDP is incapable of properly deciding the 
antecedent of PRO with the verb waead-a "promised" in (7) and also when morphologically bound dual pronoun in MSA is considered as in (8) and (9).

Hornstein [1] argues that the wrong prediction of the controller of PRO in (4) is due to the view that verb promise is a "highly marked" exception. Landau [2] states that what Hornstein assumes to be highly marked verbs seems to be pervasive in English. Landau highlights that cases of verb promise should not be treated as marked verbs as they are divided into many subcategories. These subcategories contain verbs that indicate commitment such as commit, promise, vow, and threaten, verbs referring to asking for permission such as beg, plead, petition, and ask and verbs of suggestion such as propose and suggest.

In spirit of Landau [2], MSA does not treat cases of the verb promise as exceptions. It contains a wide range of promise-type verbs which predict subject control even in the presence of an intervening argument [17]. Some of these verbs are such as talab-a "he requested", sa?al-a "he asked", tacahad-a "he vowed", haddad-a "he threatened", eqtaraћ-a "he suggested", and $\varepsilon$ arad-a "he proposed". In order to illustrate this point, consider the following examples:

\begin{tabular}{llll} 
(10) talab-a & \multicolumn{2}{c}{ s-sadgēn-u1 } & min \\
requested-he.3SG & the-prisoner.NOM from \\
?al-hāres-e & ?an & yo-daxxen-a PRO1 \\
the-guard-GEN & that & smoke-3SG.MASC PRO \\
sid3ārat-an & oxra & (subject control) \\
cigarette.ACC & another &
\end{tabular}

The prisoner requested from the guard to smoke one more cigarette.
(11) sa?al-a
s-sadgēn-u1
asked-he.3SG the-prisoner.NOM
?an yo-daxxen-a PRO1
that smoke-3SG.MASC PRO
oxra
?al-hāres-a
another
The prisoner asked the guard to smoke one more cigarette.
(12) tacahad-t-u1 li-ra?ēs-i
vowed-I.1SG to-boss-my
vowed-I.1SG to-b
PRO1 moxles-an
MSA
the-guard-ACC
sidzārat-an
cigarette. ACC
(subject control)

$$
\begin{aligned}
& \text { ?an a-qūn-a } \\
& \text { be-1SG.MASC } \\
& \text { (subject control) }
\end{aligned}
$$$$
\text { that be-1SG.MASC }
$$

MSA

PRO loyal.ADG

I vowed to my boss to be loyal.

(13) haddad-a r-radzul-u1 zawdzata-hu

threatened-he.3SG the-man.NOM wife-his.ACC

?an ya rab-a PRO1 s-sum-a (subject control)

that drink-3SG.MASC PRO the-posion.ACC

The man threatened his wife to drink the poison.

$\begin{array}{llcc}\text { (14) eqtaraћ-a } & & \text { r-radzul-u1 } & \text { Eala } \\ \text { suggested-he.3SG } & \text { the-man.NOM } & \text { to. PREP } \\ \text { Mona } & \text { ?an } & \text { ya-ðhab-a } & \text { PRO1 } \\ \text { Mona.GEN } & \text { that } & \text { go-3SG.MASC } & \text { PRO } \\ \text { ila } & \text { s-sūk-i. } & & \text { (subject control) } \\ \text { to.PREP } & \text { the-market.GEN } & & \end{array}$

The man suggested to Mona to go to the market.
(15) Earađ-a-t
proposed-she.3SG
George ?an
George.GEN that
?al-fatūra.
the-bill.ACC
Marina proposed to George to pay the bill.

\begin{tabular}{ll} 
Marina1 & \multicolumn{1}{c}{ MS } \\
Marina.NOM & to \\
tadfae-a & PRO1 \\
pay-3SG.FEM & PRO \\
\multicolumn{2}{c}{ (subject control) }
\end{tabular}

MSA

MSA

In the examples above, the null PRO subject in the embedded clause is controlled by the subject in the matrix clause. In (10) and (11) PRO is the subject of the embedded clause ?an yo-daxxen-a "to smoke". It is controlled by the matrix subject s-sadgēn-u "the prisoner". Thus, the verbs talab-a "he requested" and sa?al-a "he asked", and other verbs not mentioned here such as tarad3-a "he begged", tawassala-a "he petitioned", etc., which are classified under requesting for permission, are subject control verbs. The same interpretation applies to examples (12) and (13) which are graded under the subgroups of verbs of commitment. Examples (14) and (15) which are sorted under and verbs of proposition and suggestion have the same interpretation as well.

The previously mentioned sample of the subcategories of promise-type point out that MSA exhibits quite a large number of subject control verbs. This indicates that the cases of the verb promise are not marked in Arabic. Accordingly, this opposes Hornstein's hypothesis that promise-type cases are highly marked exceptions. Although, it is reasonable that Promise-type verbs are not as large as other types of verbs, but this does not account for either treating them as exceptions or disregarding them because, as shown above the MSA data refute this claim. Thus, the choice of the antecedent of PRO should not be dependent on the distance between the antecedent and PRO, but some semantic and pragmatic interpretation should be taken into consideration. Accordingly, the data from the MSA show consistency with Landau's view, but refutes Hornstein's hypothesis.

\section{Conclusion}

Given the result that the status of MDP is not compatible with the syntax of MSA and that promise-type verbs are not marked exceptions, the MDP, employed by Hornstein in favor of his MTC approach, is an inadequate mechanism to account for the choice of the controller of PRO in OC structures. Consequently, control structure is different from raising structure. This study is crucial as it sheds more light on the nature of the separation or the unification of control and raising and takes part in the current ongoing hot discussion concerning the distinction between them. Providing data from MSA points out that Hornstein's hypothesis cannot be generalized to it. Maintaining the control module and distinguishing it from raising does not result in the problems caused by applying the MDP to account for the MTC. Thus, this would avoid generating 
unnecessary problems.

\section{REFERENCES}

[1] N. Hornstein. Movement and control, Linguistic Inquiry, Vol. 30, No. 1, 69-96, 1999.

[2] I. Landau. Movement out of control, Linguistic Inquiry, Vol. 34, No. 3, 471- 498, 2003.

[3] C. Boeckx, N. Hornstein. Reply to Control is not movement, Linguistic Inquiry, Vol. 34, No. 2, 269-280, 2003.

[4] C. Boeckx, N. Hornstein. Movement under control, Linguistic Inquiry, Vol. 35, No. 3, 431-452, 2004.

[5] I. Landau. Movement-resistant aspects of control, In New horizons in the analysis of control and raising, Springer, Dordrecht, 293-325, 2007.

[6] P. W. Culicover, R. Jackendoff. Control is not movement, Linguistic Inquiry, Vol. 32, No. 3,493- 511, 2001.

[7] R. Jackendoff, P. W. Culicover. The Semantic Basis of Control in English, Language, Vol. 79, No. 3, 517-556, 2003

[8] P. W. Culicover, R. Jackendoff. Turn over control to the semantics, Syntax, Vol. 9, No. 2, 131-152, 2006.
[9] C. Boeckx, N. Hornstein. The virtues of control as movement, Syntax, Vol. 9, No. 2, 118-130, 2006 a.

[10] J. D. Bobaljik, I. Landau. Icelandic control is not A-movement: The case from case, Linguistic Inquiry, Vol. 40, No. 1, 113-132, 2009.

[11] M. Modesto. What Brazilian Portuguese says about control: Remarks on Boeckx \& Hornstein, Syntax, Vol. 13, No. 1, 78-96, 2010.

[12] P. Rosenbaum. The grammar of English predicate complement constructions, Cambridge, Mass.: MIT Press, 1967.

[13] A. Radford. Minimalist syntax: exploring the structure of English, Cambridge, Cambridge University Press, 2004.

[14] N. Berjaoui. The empty category principle in English and Standard Arabic, Lincom Europa, Germany, 2009.

[15] A. Fassi-Fehri. Issues in the structure of Arabic clauses and words, Dordrecht: Kluwer Academic Publishers, 1993.

[16] C. Johns. Interpreting agreement (Doctoral dissertation), Department of Linguistics and English Language, Durham University, 2007.

[17] M. Mohammad. Word order, agreement, and pronominalization in standard and Palestinian Arabic, John Benjamins, Philadelphia, 2000. 